\title{
ESPAÇOS DA PÓS-MODERNIDADE
}

Maiquel Röhrig*

\section{Resumo}

Neste ensaio, discuto o conceito de pós-modernidade. Meu ponto de partida é que a pósmodernidade existe. Porém, ao contrário do que normalmente afirmam os teóricos e a despeito da ideia de globalização, penso que o pós-modernismo consiste justamente da multiplicidade dos modos de vida, e do fato de que, em um mesmo espaço, podem conviver pessoas com pensamentos, valores e maneiras de viver distintas.

Palavras-chave: pós-modernidade; modos de vida; tecnologia.

\begin{abstract}
In this essay, I discuss the concept of postmodernity. My starting point is that the postmodernity exists. However, unlike what usually claim the theoretical and despite the idea of globalization, I think postmodernism is precisely the multiplicity of ways of life, and the fact that, in the same space, people can live with thoughts, values and ways of life differents.
\end{abstract}

Key words: postmodernity; lifestyles; technology.

A polêmica sobre o conceito e a real existência da pós-modernidade perpassou o século XX e persiste ainda hoje. Os teóricos não só divergem sobre o que ela é, como também se ela realmente existe. Há quem postule a existência de uma hipermodernidade, discordando da ideia que viveríamos em uma lógica posterior à modernidade, e afirmando, por outro lado, que o que experimentamos é a exacerbação dos preceitos e do modo de vida modernos.

Em primeiro lugar, penso que a pós-modernidade existe. Porém, ela não é onipresente, como fazem parecer muitos teóricos. Trata-se de um modo de vida peculiar do nosso tempo, mas não necessariamente do nosso ser.

O mundo, apesar de ter "encolhido" muito, continua enorme. Enquanto em uma determinada cidade pessoas com um padrão de vida médio podem comprar e usufruir de bens materiais, tecnologias para comunicação, transportes e alimentação, outras vivem suas vidas sem quase nada disso, e, dependendo de suas características individuais, nem se angustiam com essas ausências.

\footnotetext{
* Doutor em Literatura Comparada pela UFRGS (Universidade Federal do Rio Grande do Sul) e professor do Instituto Federal Farroupilha Câmpus São Borja. E-mail: maiquel.rohrig@iffarroupilha.edu.br. CV: http://lattes.cnpq.br/0151009585652683
}

DIALEKTIKÉ, v. 1, novembro 2014, p. 158-163

Ensaio submetido em agosto/2014 e aceito em outubro/2014 
Nas capitais ou em grandes cidades, a falta de mobilidade, de comunicação etc. perturba as pessoas, uma vez que o padrão imposto pela sociedade é do exacerbamento. Contudo, outras pessoas, estejam nestas mesmas capitais ou em outras localidades, nem percebem estas necessidades. Algumas acham-nas inclusive futilidades das quais pretendem manter-se afastadas. Ou não as conhecem.

Países inteiros vivem à margem do desenvolvimento tecnológico. No Brasil, por sua vez, segundo país em número de pessoas que acessam diariamente o Facebook ${ }^{1}$, há iniciativas do governo para promover a inclusão digital, visto que milhões de pessoas não a tem disponível. Além disso, há pessoas que, mesmo tendo disponível meios tecnológicos, utilizam-nos pouco, sem com isso sentir-se prejudicados.

A dicotomia campo versus cidade, interior versus capital não existe mais. Muita gente do campo vive o exacerbamento pós-moderno, assim como pessoas das capitais vivem a tranquilidade aristocrática ou a brutalidade da servidão medieval.

Algumas propriedades rurais contam com sofisticada mecanização, valendo-se de máquinas para quase todos os processos. Nelas, o trabalho árduo com a enxada é substituído pela cabine refrigerada do trator, da colheitadeira equipada com GPS e computador de bordo. E as informações do trabalho são compartilhadas em aplicativos através de conexão Wi-fi captada por tablets. Enquanto isso, fábricas utilizam mão de obra com baixa qualificação em processos industriais inspirados no fordismo-taylorismo, ou nas manufaturas do século XIX.

Ao mesmo tampo, há propriedades rurais funcionando sob a lógica feudal, com servos trabalhando para um senhor quase todo-poderoso. Ou, ainda, funcionando segundo a lógica do período escravocrata, haja vista os casos de escravos em propriedades brasileiras, estimados em 25 mil ao ano ${ }^{2}$. Enquanto, por outro lado, há empresas cujos funcionários trabalham em casa, fazendo seus próprios horários e experimentando uma lógica de trabalho jamais vista.

A pós-modernidade é precisamente a coexistência de modos de vida diferentes, ocorrendo no mesmo tempo e nos mesmos espaços, podendo estes modos de vida ser experimentados, em um mesmo dia, pela mesma pessoa.

Não é difícil encontrar quem trabalhe em uma função moderna, apertanto parafusos, no exemplo clássico, ou quem esteja submetido a uma lógica feudal do ponto de vista do

1 Fonte: http://g1.globo.com/tecnologia/noticia/2013/09/brasil-e-o-2-pais-com-mais-usuarios-que-entramdiariamente-no-facebook.html

2 Fonte: http://www.senado.gov.br/noticias/Jornal/emdiscussao/trabalho-escravo/trabalho-escravoatualmente.aspx

DIALEKTIKÉ, v. 1, novembro 2014, p. 158-163

Ensaio submetido em agosto/2014 e aceito em outubro/2014 
trabalho, mas viva, dentro de sua casa, cercado de diversos estímulos, comunicando-se, interagindo com pessoas de todas as partes do mundo sem contudo superar sua alienação.

Neste caso, a alienação da pós-modernidade exige uma nova conceituação. $O$ indivíduo alienado pós-moderno não é necessariamente um oprimido sofredor que realiza um trabalho sem conhecer seu sentido: em muitos casos, esse indivíduo satisfaz suas necessidades básicas e ainda consome o que o mercado lhe oferece como objetos de prazer; ele pode conhecer o sentido de seu trabalho ou, mesmo, saber que seu trabalho não tem sentido algum senão ser mera engrenagem de um processo de produção.

A alienação moderna estava sustentada pelo modo de produção, enquanto a pósmoderna estaria baseada no consumo. Antes, produzia-se sem saber por quê, e o sistema de produção gerava uma representação distorcida do real; hoje, a "falsa consciência" seria produzida pelo consumo. A semelhança é que, para ambas alienações, concorreria o poder ideológico da família, da escola, dos meios de comunicação de massa etc. A diferença, por sua vez, é que a escola e a família teriam perdido parte de seu poder, enquanto os meios de comunicação teriam ampliado o seu, tendo surgido, inclusive, aquele que poderia multiplicar exponencialmente as referências culturais e de valores, e que muitos aclamam como o deus pós-moderno: a internet.

No entanto, as formas de alienação são múltiplas, não se reduzindo à dicotomia produção e consumo. E o modo como vivem os alienados também: havendo inclusive aqueles que preferem cultivar sua alienação, paradoxalmente conscientes dela, para suportar a vida. E nesse aspecto a internet é especialmente interessante: oferece a oportunidade de nos defrontarmos com ideias e informações variadas, ampliando nossa percepção e o tamanho de nosso mundo; ainda que a maioria de nós se limite a procurar por aquilo que nos interessa e que ratifica ideias que já temos, deixando o nosso mundo sempre do mesmo tamanho, sem possibilidade de dilatá-lo ou modificar sua forma e conteúdo.

A lógica do consumismo aplaca o sofrimento dos alienados e não-alienados metidos no caldeirão da pós-modernidade, ou o maximiza. Porém, essa lógica não é o que caracteriza o indivíduo pós-moderno. Este não cabe em conceituações: ele simplesmente é humano, resguardado de qualquer outro rótulo. Se a pós-modernidade é a coexistência de modos de vida, o indivíduo pós-moderno não é necessariamente aquele que perambula entre o trabalho braçal, rachando lenha em uma propriedade rural, e o lazer nas redes sociais, acessadas pelo smartphone.

A pós-modernidade evidencia o caráter dialético da vida, da História e de tudo o que 
há de humano no mundo. A liquidez, como diz Bauman, é sua marca registrada. No entanto ela não significa a quebra dos paradigmas modernos, não matou deuses nem verdades, como pensou Lyotard: ao contrário, ela multiplica tudo isso e permite que vivamos um torvelinho de experiências permeadas por diversas e contraditórias ideologias.

Ou não. Pois, ao mesmo tempo, podemos viver isolados, em um bairro nobre ou da periferia, na cidade ou no interior, ligados afetivamente a um grupo pequeno de pessoas e assistindo sempre ao mesmo canal de TV. E, ainda que o mundo todo tente invadir esses espaços e penetrá-los de diferentes maneiras, muitos não o percebem.

A modernidade, por sua vez, embora pareça-nos algo muito claramente definido, não o é tanto assim. Os teóricos costumam se encastelar em seus gabinetes e ver o mundo segundo sua perspectiva, indiferentes às pessoas que não alcançam a complexidade de suas ideais. E muitas dessas ideias não são outra coisa senão simplificações da realidade que, ora é mais complexa, ora mais simples ainda.

A razão, aclamada como fundamento da modernidade, dominou o modo de produção de mercadorias, mas não o pensamento. Continuaram coexistindo ideais racionalistas e doutrinas religiosas, às vezes pacificamente, outras nem tanto. E a pós-modernidade herdou essa característica, pois uma pulverização de seitas e igrejas ocorre pelo mundo, e mesmo na ciência a imagem de deus perdura.

Os produtos modernos tinham certa estabilidade. Podia-se fabricar um equipamento por anos sem alterar o sistema de produção nem a mercadoria. Isso mudou em relação a muitas coisas, e, ao andarmos em um novo modelo de automóvel e recebermos mensagens em nosso novo celular, não vemos tudo que, à nossa volta, continua sendo fabricado segundo a lógica das manufaturas do século XIX. Tampouco enxergamos o reflexo do passado ao esbarrarmos nos artesãos que vendem seus produtos na calçada, enquanto, de cabeça baixa, preparam nova mercadoria.

Benjamin afirma que a modernidade modifica o modo como a arte é pensada e como a obra artística é executada, devido à possibilidade de produção em larga escala. Há obras que são claramente perpassadas por essa lógica: na pintura, na literatura, na escultura, na arquitetura etc. Entretanto, a generalização nos engana, uma vez que, paralelamente, muitos artistas produzem suas obras embuídos do mesmo sentimento daqueles que muito antes da modernidade pintavam, escreviam, compunham: querem alcançar o universal e manter-se vivos na posteridade, e não apenas vender seu trabalho para aproveitar um momento efêmero de sucesso.

DIALEKTIKÉ, v. 1, novembro 2014, p. 158-163

Ensaio submetido em agosto/2014 e aceito em outubro/2014 
Quando os exemplos concretos afrontam nossa tentativa teórica de ordenar o caos em que estamos metidos, recorremos a especulações sobre o futuro, e dedicamos nossa atenção à juventude. A ela, ora reservamos palavras ferinas, desconsolados porque eles não obedecem as regras que esperávamos, entretidos com seus equipamentos eletrônicos, ora lançamos-lhe nossa esperança de que no futuro ela tornará real a ideia desse mundo hiperconectado que projetamos como o presente onipresente pós-moderno.

Nos dois casos, enganamo-nos. Os jovens, ao subverterem as regras que lhes impomos, não fazem nada que os jovens modernos não fizeram. E, ao generalizarmos, dizendo que eles são de tal modo e fazem tais e tais coisas, desprezamos sua diversidade. Pois há milhões de jovens diferentes dos estereótipos que deles fazemos, e isso inclui aqueles sem acesso aos equipamentos eletrônicos que cremos caracterizar esta geração. Dentre estes milhões, muitos os desejam, outros, se os tivessem, os trocariam por um violão. Ou um livro. Ou uma bola. Ou uma arma.

Há na pós-modernidade riqueza e miséria, conectividade e solidão, velocidade e estagnação. Mas estes opostos não constituem pares antitéticos inconciliáveis como o eram antes. Hoje eles não se degladiam, convivem, ainda que travem batalhas simbólicas o tempo todo.

A diversidade de modos de vida multiplica-se. Novas leis são diariamente criadas para dar-lhes espaço ou para coibi-los. Quem pode, avalia as possibilidades, experimenta-as até enjoar delas ou ser seduzido por outra mais atrativa. Quem não quer, não entende ou não pode mantém-se como é. E se persiste algo de moderno em nossa sociedade, algo que a modernidade herdou de todas as eras que a precederam, infelizmente é isso: muitos ainda não podem, vivem sem oportunidade de escolhas, metidos num rio cujo curso os conduz a um local que eles esperam que não seja aquele que todos preveem.

A previsibilidade do futuro de um indivíduo é bem menor que na modernidade e em outros períodos. As possibilidades, ainda que em muitos casos sejam limitadas, já são maiores. Mas se há algo em que a pós-modernidade precisa superar os períodos que a precederam é o fato de que muitos, ao nascerem, têm seu futuro pré-determinado pelas condições materiais de sua existência. Porque, por mais que o mundo tenha mudado, ainda é a materialidade da vida o imperativo fundamental que faz a vida ser o que ela é.

\section{REFERÊNCIAS}

DIALEKTIKÉ, v. 1, novembro 2014, p. 158-163

Ensaio submetido em agosto/2014 e aceito em outubro/2014 
BAUMAN, Zygmunt. Amor Líquido: Sobre a Fragilidade dos Laços Humanos. Tradução de Carlos Alberto Medeiros. Rio de Janeiro: Zahar, 2004.

Modernidade e holocausto. Tradução de Marcus Penchel. Rio de Janeiro: Jorge Zahar Ed., 1998.

Vida líquida. Tradução de Carlos Alberto Medeiros. Rio de Janeiro: Zahar, 2009.

BENJAMIN, Walter. A obra de arte na era da sua reprodutibilidade técnica. Porto Alegre: Zouk, 2012.

JAMESON, Fredric. A virada cultural: reflexões sobre o pós-moderno. São Paulo: Civilização Brasileira, 2006.

Glosas marginais ao programa do partido operário alemão. Disponível em http://www.marxists.org/portugues/marx/1875/gotha/gotha.htm. Acesso em 30/05/2011.

Claret, 2001.

Manuscritos econômico-filosóficos. Tradução de Alex Marins. São Paulo: Martim

O Capital: crítica da economia política. Tradução de Regis Barbosa e Flávio R. Kothe. São Paulo: Nova Cultural, 1985, Vol. I., $2^{\mathrm{a}}$ ed.

O Capital: crítica da economia política. Tradução de Regis Barbosa e Flávio R. Kothe. São Paulo: Nova Cultural, 1985, Vol. II., $2^{\text {a }}$ ed.

O capital. Tradução de Regis Barbosa e Flávio R. Kothe. Livro Segundo. São Paulo: Nova cultural, 1988, Vol. III, $3^{\text {a }}$ ed.

O capital. Tradução de Regis Barbosa e Flávio R. Kothe. Livro Terceiro. São Paulo: Nova cultural, 1986, Vol. IV, $2^{\text {a }}$ ed.

O capital: crítica da economia política - Livro Primeiro. Tradução de Reginaldo Sant'Anna. São Paulo: DIFEL, 1985, Vol. I., 10ª ed.

O capital: crítica da economia política - Livro Primeiro. Tradução de Reginaldo Sant'Anna. São Paulo: Bertrand Brasil-DIFEL, Vol. II, 1987.

LYOTARD, Jean-François. A condição pós-moderna. 5. ed. Rio de Janeiro: José Olympio, 1998. 